\title{
Fratrias e relações entre irmãs/os ao longo da vida: uma perspetiva sociológica
}

\author{
Phratries and relationships between siblings \\ throughout life: a sociological perspective
}

\author{
Andreia Barbas* (iD \\ Sílvia Portugal ${ }^{*}$ (D)
}

\begin{abstract}
RESUMO
As relações entre irmãs ou irmãos têm merecido escassa atenção na Sociologia face a outras dimensões do fenómeno familiar. Este artigo pretende contribuir para contrariar essa tendência, e mostrar como este é um objeto merecedor de um olhar sociológico atento. O texto parte de uma pesquisa qualitativa, que realizou 32 entrevistas, com caráter de história de vida, a membros de fratrias pertencentes a famílias nucleares. Adotou-se uma perspetiva longitudinal, cruzando as diferentes fases de vida (infância, juventude e idade adulta), que permitiu revelar o dinamismo dessas relações ao longo do ciclo de vida, e sua cristalização na idade adulta. O artigo pretende responder a duas questões: a) o que é ser irmã ou irmão?; b) como se caraterizam as relações fraternais? As relações observadas revelaram-se plurais e complexas, mostrando a relevância de cinco dimensões para a sua análise: biológica, normativa, afetiva, estatutária e comparativa. A partir das narrativas dos sujeitos foi possível identificar relações vinculativas, companheiristas e de aliança. A discussão levantada neste artigo tem como propósito fornecer elementos e ferramentas analíticas com valor heurístico para a análise deste objeto.
\end{abstract}

Palavras-chave: irmãs e irmãos, fratrias, família, relações familiares.

* Universidade de Coimbra, Coimbra, Portugal. 


\begin{abstract}
Relationships between siblings only recently started to receive attention in Sociology, when compared with other dimensions of the family phenomenon that are already extensively studied. This article intends to be a contribution to counteract this trend and to show how this subject is worthy of a close sociological approach. The work is based on qualitative research composed of interviews, based on life history, with 32 subjects comprising siblings in nuclear families. In this study, a longitudinal perspective was adopted, spanning various stages of life (childhood, youth, and adulthood), which allowed to demonstrate the dynamism of these relationships throughout their life cycle, and their manifestation in adulthood. The article aims to answer two questions: a) what does it mean to be a sibling? b) how are siblings' relationships characterized? The relations between siblings proved to be plural and complex, showing the relevance of five dimensions for their analysis: biological, normative, affective, statutory, and comparative. Based on subjects' narratives, it was possible to identify binding, companionship, and convenant relationships. The discussion raised in this article aims to provide elements and analytical tools with heuristic value for the analysis of this object.
\end{abstract}

Keywords: brothers and sisters, siblings, family, family relationships.

\title{
Introdução
}

Assiste-se, hoje, em Portugal (e no mundo), a um declínio da fecundidade, representada pela diminuição da dimensão média das famílias, pelo aumento do número de casais sem descendentes, pela percentagem de crianças nascidas fora do casamento, por quem tem um só filho ou filha. A taxa de divórcio é crescente, testemunha-se o acréscimo das famílias monoparentais, tal como ao aumento das famílias recompostas e de casais com filhas/os não comuns. Estas alterações afetam substancialmente as estruturas familiares contemporâneas e, consequentemente, as fratrias. Observa-se uma diminuição do número de irmãs/os, assim como a amplitude etária entre si, por comparação às gerações anteriores. As recomposições familiares dão origem à crescente realidade de meios-irmãos e de “irmãos sociais” (que não têm ascendentes em comum). 
Só nos últimos anos, as fratrias emergiram como objeto significativo para as Ciências Sociais e, especificamente para a Sociologia. Vem-se, assim, contrariando uma invisibilidade notória, sobretudo por comparação com outros fenómenos familiares como a conjugalidade ou a parentalidade (Bedford, 1989; Roussel, 1989; Widmer, 1999; Buisson, 2003; Barroso, 2011). O desinteresse sociológico pelas fratrias prende-se, em grande parte, à sua condição de "acessórios familiares" das mães e dos pais, desconsiderando suas dinâmicas relacionais específicas (Buisson, 2003; Barbas, 2014; Portugal, 2014). No entanto, surgem, frequentemente, nos discursos de "outros" sujeitos e, também, no âmbito de pesquisas com temáticas diferenciadas, revelando a transversalidade da sua importância para além das fronteiras da Sociologia da Família (Silva et al., 2011; Portugal, 2014).

Atualmente, os trabalhos que têm vindo a ser desenvolvidos mostram como este objeto é multifacetado e merecedor de atenção e destaque (Punch, 2008; Barroso, 2011; Gulløv et al., 2015; White \& Riedmann, 2016; Davies, 2019). As investigações já realizadas têm revelado múltiplas dimensões analíticas e particularizam sua análise numa fase de vida (infância, juventude ou idade adulta). Identifica-se como a morfologia das estruturas familiares e eventos que ocorrem ao longo das trajetórias de vida têm impacto nas vidas de pessoas irmãs, gerando diferenças e desigualdades entre as mesmas (Dalton, 2004). Assinala-se, também, o sentimento dualista amor/ódio presente nas fratrias, devido ao conhecimento mútuo, propiciado pelo tempo e espaço que os elementos das fratrias partilham (Punch, 2008). Critica-se a sua ausência nas teorias sociológicas da identidade, pois as relações fraternais podem ser estruturantes na definição de identidades e na construção do self (Davies, 2015). A avaliação do impacto que o suporte financeiro intergeracional pode ter na conceção de justiça na fratria surge também no contexto das investigações sobre o tema (Heath, 2018).

A pesquisa que dá origem a este texto teve como objetivo visibilizar as relações fraternais enquanto objeto sociológico. Estudaram-se fratrias nucleares, que têm ambos os progenitores em comum. Usando uma abordagem qualitativa, consideraram-se as narrativas dos próprios sujeitos como forma de acesso às caraterísticas das fratrias e às perspetivas subjetivas das relações. As entrevistas foram realizadas num processo de coconstrução da narrativa que, ao abordar as diferentes fases do ciclo de vida (infância, juventude e idade adulta), favoreceu uma articulação do passado com o 
presente e possibilitou, também, uma perspetiva de entendimento quanto ao futuro, ancorada nas experiências anteriores (Bruner, 1987; Duncombe \& Marsden, 2003; Thomson et al., 2002; Smart, 2006). Procurou-se, assim, como proposto por Smart (2006), minimizar a reatividade a acontecimentos particulares e estabelecer conexões entre experiências/eventos, refletindo sobre o passado. O mapeamento das trajetórias permite compreender a evolução das relações, identificar momentos de aproximação/afastamento e atribuir sentido às variações.

Pouco se conhece sobre essas relações de parentesco. Os discursos socialmente generalizados (nomeadamente através dos meios de comunicação social e da cultura de massas) associam as relações fraternais a valores de amor e harmonia familiar, difundindo uma imagem unívoca de um tipo de relações que aqui se defende serem plurais e complexas. Partindo dos discursos dos sujeitos entrevistados, este artigo pretende questionar a homogeneidade e conformidade das narrativas acerca das fratrias, tomando como objetivo responder à questão: afinal o que é ser irmã ou irmão? Numa primeira parte do texto, explora-se o(s) significado(s) dessas relações familiares, revelando a diversidade de elementos que as estruturam. Numa segunda parte, agrupa-se as narrativas para caraterizar as dinâmicas das fratrias. Como refere Smart (2006), agrupar as narrativas deve ser entendido como uma ferramenta analítica que procura alcançar algumas semelhanças e diferenças nos relatos das pessoas entrevistadas, estando sempre sujeitas a mudanças, e rejeitando um caráter fixo das relações (Smart, 2006). Analisando-se os discursos sobre as experiências, os eventos familiares, os quotidianos e as interações, identificaram-se três grupos de narrativas que permitem descrever a pluralidade que carateriza as relações fraternais: as relações vinculativas, as companheiristas e as de aliança.

\section{Considerações metodológicas}

A pesquisa que dá origem a este texto assenta-se em 32 entrevistas semi-diretivas com um caráter de história de vida, realizadas a irmãs/os. Recuperando a ideia do "empirismo irredutível” das entrevistas apontado por Kaufmann (1996, p. 16), ao citar Schwartz, considerou-se que esta técnica apresentaria diversas vantagens para o entendimento das relações 
fraternais, dando conta da sua complexidade. O caráter de narrativa biográfica acrescentou o olhar longitudinal, e permitiu obter uma descrição detalhada das trajetórias, situando os momentos mais marcantes das relações e compreendendo os sentimentos, pontos de vista e perspetivas dos membros das fratrias (Atkinson, 2016). Especificamente, olhou-se para: (i) a história da família nuclear; (ii) as relações com os membros da família nuclear (continuidades e mudanças); (iii) o quotidiano da família nuclear (passado e presente); (iv) o impacto das práticas educativas parentais nas relações fraternais (passado e presente); (v) a prestação de cuidados (passado, presente e/ou expectativas futuras); (vi) herança familiar (passado, presente e/ou expectativas futuras).

A seleção das fratrias foi feita a partir de redes de interconhecimento das investigadoras e, após esse contacto, a escolha do segundo elemento da fratria foi da responsabilidade da primeira pessoa contatada que se mostrou disponível para participar na investigação. Os nomes das pessoas participantes que se encontram ao longo deste texto são fictícios e foram atribuídos pelas investigadoras.

As entrevistas realizaram-se de forma individual a dois elementos da fratria. Pretendeu-se ouvir duas pessoas de cada fratria de forma a trazer maior riqueza e diversidade de informação, rejeitando uma postura de comparação dos discursos numa procura de "verdade analítica”, isto é, o propósito foi compreender o lugar de cada sujeito e a sua interpretação individual face à sua posição na fratria. Na apresentação da pesquisa, assegurou-se aos sujeitos que a informação facultada por cada um não seria cruzada durante as diferentes entrevistas. Escutar mais do que um membro da fratria permitiu visibilizar diferentes perspetivas, compreender o lugar de cada um/a na família e refletir sobre significado(s) e (dis)sonâncias.

O estudo considerou pessoas com irmãos inseridas/os em famílias nucleares e em dois intervalos etários (especificamente, dos dezasseis aos trinta anos e a partir dos quarenta e cinco anos). A seleção dos grupos etários fez-se por referência à data da revolução de 25 de abril de 1974, tomando esta como um ponto cronológico que permite observar o antes e depois da democratização nas práticas e representações familiares (Guerreiro et al., 2007). Diferentes zonas geográficas, locais de residência (rural ou urbano) e contextos socioprofissionais das famílias encontram-se refletidos na amostra selecionada, de modo a possibilitar uma maior heterogeneidade. 
Por se reconhecer que o número de elementos que compõem a fratria é uma caraterística a ter em consideração quando se trabalha sobre este tema (Merry et al., 2020), procuraram-se fratrias com diferentes dimensões: binárias (compostas por dois elementos), tríades (compostas por três elementos), ou alargadas (com quatro ou mais elementos). Sabe-se, também, que a composição sexual deve ser igualmente tida em consideração quando se trabalha sobre fratrias (Barroso, 2011) e, por isso, todas as tipologias foram abrangidas: mistas, masculinas e femininas. A definição da amostra foi, assim, construída com base na seleção de casos ricos em informação para uma investigação aprofundada, em detrimento de generalizações empíricas (Patton, 2002). ${ }^{1}$

Os resultados aqui apresentados dizem respeito a um grupo composto por 16 pessoas entrevistadas entre os 17 e os 30 anos (sete homens e nove mulheres) e outras 16 a partir dos 45 anos (dez mulheres e seis homens). Relativamente à dimensão das fratrias, sete são binárias (compostas por dois elementos), quatro tríades (compostas por três elementos) e cinco alargadas (compostas por quatro ou mais elementos). Sobre a composição sexual, identificam-se nove fratrias mistas, três femininas e três masculinas.

Esta investigação foi, desde o início, um desafio, principalmente, pela escassa bibliografia sobre a temática em Portugal. Assim, as entrevistas revelaram-se absolutamente essenciais na construção da investigação, e foi através delas, e com uma grande abertura à indução, que se concretizou a investigação e valorizou a riqueza da informação recolhida, explorandose as narrativas dos sujeitos. A análise das diferentes fases do ciclo de vida possibilitou dar conta das (re)configurações familiares e estabelecer conexões entre as relações dos sujeitos, e entre os ciclos de vida.

\section{O que significa ser irmã ou irmão?}

No discurso das pessoas entrevistadas, foi possível encontrar cinco dimensões para a definição do que é ser irmã/o, reiterando o que Barroso (2006) identificou no seu trabalho: (i) a dimensão biológica, que contempla a consanguinidade inerente às relações familiares; (ii) a obrigatória, que advém da imposição subjacente às relações fraternais, tal como às outras relações

\footnotetext{
${ }^{1}$ A seleção deixou de fora irmãos adotivos, irmãos com deficiência, e meios-irmãos. Considerou-se que estes têm especificidades, que merecem ser observadas de modo particular, tal como mostra a literatura (Burke \& Montgomery, 2000; Steinbach \& Hank, 2018; White \& Riedmann, 1992).
} 
de parentesco; (iii) a afetiva, definida pela sentimentalização da família e pelos valores de amor e de amizade; (iv) a estatutária, que evidencia uma função identitária, a partir do lugar de cada pessoa na fratria, mas também de estatuto, revelando o que é permitido ou não a cada uma delas; (v) por fim, a comparativa, estabelecida na horizontalidade das relações intrageracionais.

A dimensão biológica é fundamental na definição do que é ser irmã ou irmão. As relações fraternais ancoram-se na importância da consanguinidade que, embora não seja exclusiva das relações entre pessoas irmãs, assume uma enorme relevância na sua configuração. A normatividade, que se articula com a importância do laço de sangue, surge, assim, também, como um atributo relevante nessas relações Barbas, 2014; Barroso, 2008; Punch, 2008). A história comum oferece um sentimento de pertença e de permanência numa história familiar que se desenrola ao longo do tempo (Elgar \& Head, 1999; Edwards et al., 2006; Punch, 2008). Essa normatividade é particularmente relevante na fase de infância e juventude, por dois motivos: o momento da coabitação e a influência das/os ascendentes. O facto de os elementos viverem juntos durante um grande período das suas vidas propicia um (re) conhecimento mútuo e obriga à resolução da dissonância (ou tentativa de), pois a dissolução da relação é uma impossibilidade.

Eu penso que é assim. Como nós não temos nada a ver uns com os outros [irmãs/os], é preciso termos aquele coiso mesmo de família. (...) por sermos família, nunca nos separamos, aconteça o que acontecer. [Benedita, 45 anos, fratria mista alargada]

Consanguinidade e normatividade são fundamentais para que os laços fraternais se definam enquanto elemento de estabilidade e permanência e contribuam para a construção de um "nós" familiar. Como afirma Langevin (1996), irmãs ou irmãos são fundamentais para garantir a perenidade do parentesco e a indefetibilidade da família.

A afetividade é outra dimensão estruturante das relações fraternais - "ser irmã ou irmão" inscreve-se em valores como o amor, a intimidade, a confiança e a partilha. No entanto, os afetos entre os elementos são mediados pelas afinidades pessoais - os "feitios" são justificações apresentadas nos discursos para explicar maior ou menor intimidade e proximidade, assim como para permear os laços perenes de sangue e obrigação. As dimensões biológica e 
afetiva entrecruzam-se nas relações fraternais, como nas restantes relações familiares da contemporaneidade. No entanto, na maioria dos discursos, a afirmação dos valores afetivos é preponderante e relativiza a importância do laço biológico face ao amor fraternal.

Eu gosto muito do meu irmão e, pronto... acho que a coisa mais importante que eu tenho na vida é o meu irmão. [Aurora, 22 anos, fratria mista binária]

As relações fraternais integram, ainda, uma dimensão estatutária. Irmãs e irmãos identificam-se como membros de um grupo, em resultado de uma partilha de vida, de histórias individuais e familiares (Barroso, 2008). A ordem de nascimento e a consequente posição na fratria é, igualmente, estruturante (Dalton, 2004; Punch, 2005, 2008; Heath, 2018). Ser o mais velho, o do meio, ou o mais novo, ou outra combinação, implica diferentes papéis e diferentes representações, contrariando o princípio da igualdade. Em função do estatuto, estabelecem-se expectativas normativas no interior da fratria e entre pais, mães e seus filhos. Como refere Punch (2005), essas expectativas são reforçadas pelos meios de comunicação, nos retratos ficcionais das relações fraternais, e nas práticas promovidas pela educação. A posição na fratria cruza-se com as questões de género, nomeadamente, através das obrigações do trabalho e do cuidado (Barroso, 2011), complexificando a dimensão estatutária.

A interpretação do estatuto pode ser divergente em função das relações horizontais ou verticais. Ascendentes e descendentes podem ter entendimentos diferentes relativamente ao estatuto de cada membro da fratria - dissonância que, segundo as pessoas entrevistadas, é potenciadora de conflitos no âmbito desta. Por exemplo, a delegação de competências parentais a irmãs ou irmãos mais velhos foi uma questão que surgiu repetidamente nas entrevistas. A responsabilização dos mais velhos pelo cuidado dos restantes elementos da fratria é uma das atribuições que mais gera conflitos inter e intrageracionais. Os exemplos de parentalização são diversos: apoiar nos trabalhos escolares; cuidar quotidianamente; vigiar e repreender; dar o bom exemplo; realizar e distribuir tarefas domésticas; partilhar sociabilidades. No caso das fratrias femininas e mistas, a presença de um elemento do sexo feminino transporta, em geral, essa responsabilidade para as mulheres. 
A minha mãe descurou um bocado o papel dela - de mãe - e passou um bocado para a minha irmã, que acho que é uma coisa completamente errada. Acho que o mais velho tem direito à vida dele, com algum cuidado, que sempre é um exemplo para o mais novo (...) essa tendência dos pais se fazerem substituir à custa do irmão mais velho acho que foi, para mim... não é um trauma, mas acho que foi um grande problema, para mim e para a minha irmã. Para a minha irmã, porque a sobrecarregou. Para mim, porque me privou do contacto mais habitual com pessoas da minha idade e de crescer ao mesmo ritmo que os outros. (...) acho que o grande erro na nossa educação foi esse. Não vou dizer que seja tudo mau (...) eu nunca tive só uma mãe, sempre tive duas. [Maria, 45 anos, fratria feminina binária]

A diferenciação estatutária conflitua com a conceção de igualdade que domina atualmente as representações acerca da família e da parentalidade (Buisson, 2003; Montandon, 2005). Sempre que ascendentes delegam seu papel parental a algum de seus filhos, é gerada uma situação de desequilíbrio que pode levar ao conflito na fratria. A dissensão gera-se porque, por um lado, os demais membros não reconhecem autoridade a quem esta foi delegada e, por outro, surge um sentimento de injustiça por parte da pessoa parentalizada, pela assunção de uma responsabilidade não desejada e não reconhecida:

Acho que me calhou ali um bocado de responsabilidade em cima. Eu já tinha sempre responsabilidade pela Mafalda, não é? Que é mais miúda. "Olha sempre pela tua irmã [dizia a mãe]”. Depois, aí, a minha mãe sai de casa [entra no mercado de trabalho] e é ainda mais. Tenho que controlar a Mafalda, mas... Ou seja, ela não me vai ver como mãe, nunca, não é? Então, é claro, imagina, eu, com onze anos, a tentar dizer à minha irmã que tínhamos de fazer tal coisa. Porque, com a minha mãe, sempre tínhamos tarefas de casa para fazer. Chegava a casa e dizia: "Vá, agora estende isso e não sei quê." E começámos a participar mais nas tarefas de casa, porque a minha mãe, ainda por cima, não estava. Antes, ajudávamos a minha mãe. Aí, começámos a fazer as coisas pela minha mãe. A ir estender a roupa, a ir fazer as camas, tudo mais. E querer impingir algo à Mafalda, sendo que eu não sou a mãe dela, e que a mãe dela é a minha mãe, torna-se muito difícil no início pelo... Não é? Pela rebeldia da Mafalda e pela falta de respeito... [a irmã dizia]: "Faço o que me apetece!" [Mariana, 24 anos, fratria feminina binária] 
A desigualdade pode ter um sentido negativo ou positivo. Num ou noutro, as perceções são sempre construídas numa dimensão relacional e contextual. Vejam-se as interpretações de Salvador e Leonor:

Talvez eu tenha sido um bocado... eu tenha tido um bocado mais de coisas que os meus irmãos, porque, também passei mais tempo com os meus pais e quando eles [irmãos] vieram para [local] eu fiquei lá em casa sozinho com eles. E era... E viam-me mais ou menos como o filho preferido, talvez tenha sido o mais mimado. [Salvador, 20 anos, fratria mista alargada]

Comecei a sair com ele, comecei a sair à noite com o meu irmão. Eu tenho noção que comecei a sair mais cedo do que as minhas amigas, mas... Também, porque ele [o irmão] era mais velho, e como era mais velho tomava conta de mim. E então, porque, na altura, em conversas com elas, noto que... Elas só começaram a sair um ou dois anos depois de eu já andar a sair com o meu irmão e... foi mesmo pelo facto de ele ser mais velho que eles [os pais] me davam liberdade, porque ia com ele e sentiam-se mais, mais seguros. [Leonor, 22 anos, fratria mista binária]

A dimensão comparativa articula-se de modo particular com a anterior. "Ser irmã ou irmão" é, por definição, um atributo relacional e a horizontalidade que as relações fraternais comportam implica uma dimensão de comparação particular. Essa comparação é realizada tanto pelos elementos da fratria como pelos ascendentes. Ou seja, não só os sujeitos se comparam entre si, como também as mães e os pais comparam as/os filhas/os. Os relatos das entrevistas revelam como essa prática de comparar descendentes pode ser, também ela, problemática e geradora de conflito. As mães e os pais recorrem à comparação usando, sobretudo, duas estratégias: uma de sentido positivo e outra de sentido negativo. A primeira pretende uma aproximação a determinada conduta desejável, ou seja, ascendentes selecionam comportamentos e atitudes de um filho ou uma filha para estimularem os outros elementos da fratria a seguirem o seu exemplo, recorrendo a casos concretos para ilustrar as suas expectativas; a segunda fomenta o afastamento, evidenciando os aspetos que consideram negativos e que pretendem evitar nos outros elementos da fratria. Independente do seu sentido, os descendentes identificam a comparação como uma prática educativa contraproducente, porque querem ver reconhecida sua singularidade, como está exposto neste excerto do Nuno: 
A minha mãe cometia muitas vezes o erro de fazer comparações, em determinados aspetos, com o meu irmão mais novo. Às vezes era... era... era automático. Não era, não era uma coisa pensada, era só... sei lá, por exemplo, não por causa de notas, nem nada disso, que sempre fomos muito equivalentes, em escola. Aliás, houve, até, uma altura que, no secundário, teve [o irmão] melhores notas que eu. E houve, até, uma altura que a minha mãe dizia: "Vês? (...) o teu irmão na Escola Secundária até ganhou, foi dos melhores alunos da escola, do secundário inteiro, até ganhou prémios!”. E, e a minha mãe dizia: "Não ganhaste nada disto, e o teu irmão ganhou." E... Para mim isso nunca surtiu um efeito negativo, enquanto, para ele [irmão], algumas comparações que existiam devem ter surtido algum efeito negativo. Por exemplo, o facto de, se calhar, ele, a uma dada altura, ter ficado uma pessoa mais fechada. A minha mãe, às vezes, por exemplo, a gente recebe um familiar e ele não dizia nada... E eu a falar bem com as pessoas e ele não falar. E a minha mãe, às vezes: "Estás a ver? O teu irmão é simpático com as pessoas e tu não sabes ser simpático!” Esse tipo de comparações, se calhar, devem-no ter marcado de alguma forma. Ou outras comparações idênticas. Ah... Isso pode ter sido um grande erro da minha mãe e eu, a determinada altura, comecei a dizer à minha mãe que ela não devia fazer isso. [Nuno, 30 anos, fratria masculina binária]

As cinco dimensões acima apresentadas mostram os significados dessa relação de parentesco. Mas como se gerem as relações fraternais ao longo das diferentes fases da vida? Até que ponto as formas relacionais são dinâmicas? Existem acontecimentos que podem alterar as relações? As respostas a essas perguntas mostram o seu caráter variável, plural e contextual.

Como referem alguns autores (White, 2001; Barroso, 2006), as relações entre irmãs ou irmãos são das que têm maior durabilidade no tempo. Em termos etários, a probabilidade desses elementos familiares estarem presentes ao longo de toda a sua vida é elevada. Naturalmente, devido à sua longevidade, essas relações se encontram sujeitas a uma maior variação. As narrativas mostraram que as relações fraternais são marcadas pelas fases do ciclo de vida: infância, juventude e idade adulta. A infância é, sobretudo, caraterizada pela partilha: de vivências, de objetos, de memórias - os quartos são partilhados, tal como os brinquedos, as roupas, os livros, as relações e as recordações são construídas coletivamente. A dependência, intrínseca à infância, faz com que as relações fraternais sejam, também elas, dependentes 
das disposições parentais. Já na juventude, com a crescente autonomia individual, vão-se construindo limites, sendo o conflito mais marcado nesta fase, e observam-se tanto períodos de aproximação como de afastamento. Importa referir que essa emancipação individual, nessa fase, não esvazia a alçada das mães e dos pais na mediação dos seus conflitos, e sobre o entendimento que consideram ser o indicado sobre seus relacionamentos.

A idade adulta corresponde a uma consolidação das relações. Isto é, os sujeitos associam esta fase do ciclo de vida, a uma maior liberdade na gestão das suas relações, pela ausência de coabitação e pelo poder de escolha sobre a participação na vida uns dos outros. As sociabilidades e a frequência dos contactos são geridas com maior autonomia, havendo uma diminuição da intervenção das mães e dos pais. As relações entre irmãos tornam-se, assim, na vida adulta, mais independentes. Não significa isto que as relações fraternais sejam inalteráveis. As narrativas mostraram, também, que existem momentos/episódios que podem alterar a dinâmica relacional já firmada. Diversos acontecimentos marcantes que impactam e reconfiguram as relações: a entrada de um ou uma cunhada na família; o nascimento de uma criança; o divórcio de um elemento da fratria; o adoecimento de um membro da família. Esses eventos produzem reconfigurações que tanto podem assumir um caráter singular e transitório, como alterar toda a dinâmica até aí estabelecida.

Com base nessas características, de seguida, agrupa-se as narrativas dos sujeitos entrevistados retratando as relações fraternais, tal como descritas pelas partes das fratrias. Confrontando semelhanças e diferenças nos discursos, identificou-se três grupos de narrativas - relações vinculativas, relações companheiristas e relações de aliança - que permitem caracterizar a pluralidade e complexidade das relações fraternais.

\section{As relações vinculativas}

As relações vinculativas são caracterizadas pela importância da consanguinidade na definição das relações. Entre os casos estudados, o laço biológico impõe-se e determina a obrigatoriedade da relação entre os elementos da fratria, estabelecendo um laço indissolúvel. O vínculo assume particular destaque, é ele que decreta a continuidade da relação, “aconteça 
o que acontecer”. As entrevistas revelam o peso da normatividade que liga família e afeto - dificilmente, as pessoas assumiram ter uma relação pouco afetiva com seus irmãos ou irmãs. Tal como em outras relações de parentesco, a pressão social para a harmonia e o conformismo é forte (Poeschl, 2000; Portugal, 2014). Como refere Barroso (2008), as relações intrageracionais são entendidas como "relações saudáveis", que devem evitar o desacordo e o conflito, não só nas práticas, como nas representações. Identificou-se nas narrativas formas relacionais definidas prioritariamente pela obrigatoriedade do laço, assumida como estruturante e inquestionável.

Vou uma vez por semana à casa deles, parece que é pouco, mas é muito (...) as relações são muito, são muito complexas... Nós com os outros. E os irmãos? Os irmãos é que não dá mesmo (...) se não fossemos todos irmãos já estávamos despachados de três ou quatro. Pronto. E dedicava-me só àqueles. Só que eu não posso. São seis, temos sempre que fazer aquele esforço mesmo que a gente não queira. Mesmo que a gente não possa naquela hora, temos que... estar disponíveis para a família, não é? O que é que se diz? Portanto, aconteça o que acontecer eles estão lá. Mas não é fácil, a família é um karma. Só tendo para se ver. É tudo muito giro, as festas de Natal, na Páscoa, se fosse só assim. Porque depois também existe o bem e o mal e o mal também se requisita. Falta-me isto, tenho isto, dói-me aquilo. E nós temos de estar disponíveis para isto. E influencia também o nosso bem-estar, não é? Põe-nos bem e põe-nos mal. São relações impostas. [Benedita, 45 anos, fratria mista alargada]

Nessas relações vinculativas, o jogo entre obrigatoriedade, afetividade e liberdade é mediado pela relação parental e pelas afinidades pessoais. À preponderância da autoridade intergeracional na infância e juventude, sucede-se a autonomia da idade adulta. Embora prevaleça o vínculo da consanguinidade, as relações são mediadas por fatores como a proximidade geográfica. Enquanto as/os irmãs/os partilham a mesma casa e o mesmo grupo de amigas/os, e existe uma convivência quotidiana ancorada na coabitação, a relação submete-se e permanece. Na fase adulta, se existe distância geográfica, esta abre espaço à distância relacional. A sociabilidade passa a ser pontual e ritualística - por exemplo, em eventos como o Natal, aniversários, ou outras épocas festivas. Os contactos entre os elementos da fratria são escassos e, dificilmente, têm encontros que extravasam 
os tradicionais "momentos de família”. É na fase adulta que existe uma diluição da interferência dos ascendentes sobre os descendentes e as mães e os pais têm maior dificuldade em fazer prevalecer e impor sua vontade nas relações fraternas. Especialmente, quando um ou ambos os ascendentes morrem, essas relações de parentesco ficam "por sua conta" e reduzem a sociabilidade. Não “fazem por estar” na vida das irmãs ou irmãos e já não se julgam obrigados a fazê-lo.

\section{As relações companheiristas}

Essas relações são estruturadas pelo laço afetivo, em detrimento do laço biológico. Os valores inscritos na relação fraternal são sobretudo de amor e amizade. A dimensão estatutária dilui-se na forma igualitária como se constroem as relações, minimizando os conflitos. Existe uma forte sociabilidade, consolidada em contatos formais e informais. No reverso das relações vinculativas, nesta relação, antes de se "verem como irmãs", as pessoas veem-se como amigas. O alicerce da relação está na dimensão relacional e, não tanto, na biológica. A pessoa irmã é identificada como aquela com quem se tem uma relação assente no amor, intimidade e confiança. A proximidade etária é um dos fatores que potencializa essas relações, permitindo afinidade de interesses e aproximação relacional. Os relatos aqui agrupados caracterizam uma vida partilhada, que é desejada e apreciada, e caracterizam-se por serem confidentes e fonte de apoio.

A partilha favorece e é favorecida pela existência de redes comuns de amizade. Irmãos companheiristas circulam entre redes de amizade. O círculo fraternal de sociabilidades é alargado e potencia uma convivência para além da residência e das dinâmicas familiares.

Nós temos um grupo de amigos em comum. Que até, normalmente, quando ele [o irmão] está cá eu vou primeiro ter com as minhas amigas, vamos beber café e não sei quê, quando elas vão para casa eu vou ter com eles [o grupo de amigos em comum] até mais tarde, temos sempre aquele grupinho de amigos em comum. [Leonor, 22 anos, fratria mista binária]

A partilha do quotidiano, de redes relacionais, de experiências de vida promove a confiança e a cumplicidade. Nessas relações é característico que se tentem proteger, desenvolvendo um espírito de "equipa”. Não lutam 
só entre si, mas também para si. Por um lado, não têm problemas com o desacordo interno porque sabem que essas questões conflituantes não colocam em causa suas relações, pela força que os laços assumem nessas relações. Por outro lado, o conflito com os ascendentes fortalece o "nós" fraternal - pois, intercedem uns pelos outros, tecendo uma teia cúmplice de interesses geracionais.

Em relação a isso de beber uns copos, e ficar mal, aí protegemo-nos bué um ao outro. Tanto que a minha irmã só foi apanhada algumas vezes e foram aquelas que eu não consegui controlar. Nisso aí protegíamo-nos bué. [Rodrigo, 23 anos, fratria mista binária]

Com base nas narrativas, essas relações caracterizam-se pela facilidade e fluidez com que se instituem. Se, na infância e na juventude, a coabitação promove a proximidade relacional, a distância física que acontece na idade adulta (suscitada sobretudo por questões de percurso escolar ou laboral) não se traduz em distância relacional. As pessoas entrevistadas afirmaram que facilmente se adaptam e respondem positivamente aos desafios do afastamento físico. As estratégias para lidar com a distância geográfica e manter a proximidade relacional são diversas. Utilizam as novas tecnologias para manter contato diário através da troca de e-mails, chamadas via Skype, entre outras plataformas digitais, removendo as barreiras geográficas (Hamwey et al., 2018). Identifica-se, também, o agendamento de fins-desemana e férias em locais geograficamente estratégicos e intermédios, bem como visitas às casas de cada um/a. Quando se voltam a encontrar, referem que "é como se o tempo não tivesse passado por elas" e não há qualquer constrangimento introduzido pela distância geográfica.

\section{As relações de aliança}

As relações de aliança estabelecem-se a partir da consanguinidade e vãose construindo com base na dimensão afetiva, tendo as duas dimensões um peso equivalente. É partilhada uma história e um “nós” relacional muito forte, em função de uma presença continuada ao longo das trajetórias de vida. As relações fraternais de aliança caracterizam-se por serem muito intensas, assumindo um caráter permanente e de indissolubilidade. A durabilidade e a intensidade dessas relações conferem-lhe um título "à prova de tudo". Por 
analogia com os laços matrimoniais, esse tipo de relações fraternais é para manter "na saúde e na doença, na alegria e na tristeza, amando e respeitando até que a morte os separe”. A obrigação dos sujeitos que integram essas relações de aliança é "estarem lá, aconteça o que acontecer”.

Mais uma vez, tal como no matrimónio, deve-se respeitar o outro. Quer isto dizer que o conflito deve ser evitado ao máximo, sendo constantemente menorizado. As caraterísticas pessoais de cada parte tendem a ser subvalorizadas mediante os valores de consanguinidade - aceita-se o “feitio" uns dos outros. Os valores privilegiados vão ao encontro de representações, amplamente invocadas, como a harmonia, a consonância e a conformidade. Estar em desacordo ou em conflito é sempre algo a evitar. Nos discursos das pessoas entrevistadas surgiram, frequentemente, frases como "temos de compreender", "é lá o feitio dela/e”, "temos que respeitar”, de modo a amenizar questões que, visivelmente, são do desagrado das pessoas entrevistadas.

Nas entrevistas, foram recorrentes as afirmações de que sempre estiveram presentes nas vidas das/os irmãs/os, independentemente da fase do ciclo de vida - infância, juventude ou idade adulta. Apontam inúmeros acontecimentos que pontuam uma vida conjunta: os mais marcantes casamentos; nascimentos de filhos; nascimentos de sobrinhos; batizados; perda de familiares; divórcios; a morte dos ascendentes. Os rotineiros chamadas telefónicas diárias; passeios aos fins-de-semana; férias conjuntas; transporte das crianças para a escola; participação nas festas de aniversário. Destacam o suporte em situações de urgência, o apoio emocional e as ajudas continuadas em bens e serviços. As intensas trocas materiais e emocionais são potenciadas pela proximidade geográfica, que, ao longo da vida, promove uma presença quotidiana e fomenta a proximidade relacional.

Sinto que agora estamos mais ligadas uma à outra [entre irmãs]. Primeiro porque a vida assim o condicionou... porque depois eu tive filhos e ela ajuda-me nos filhos, nas minhas filhas, ajudou-me a criálas, depois ela tem filhos e eu estou sempre... também não somos aquelas irmãs que estamos distantes geograficamente (...) mas apesar de todas as nossas desavenças, de todas as nossas diferenças, de muita coisa... de não coincidirmos nas ideias, não. Somos totalmente diferentes, apesar de tudo isso, eu não conseguiria estar separada, não era só fisicamente, ou não participar na vida da minha irmã. [Rita, 53 anos, fratria feminina binária] 
Estes laços fraternais caracterizam-se por um familismo "simultaneamente, instrumental e expressivo, preenchendo necessidades materiais e afetivas" (Portugal 2014, p. 209). Nessas relações os laços estabelecidos entre os membros da fratria são fortes, sustentados na importância que as duas principais dimensões - sanguínea e afetiva - assumem. Os laços fraternais têm um caráter permanente e duradouro, apoiado na consanguinidade e consistência da relação afetiva. Os fluxos são intensos e a diversidade dos seus conteúdos, também. Os laços fraternais são ativos nos mais diversos tipos de apoio e estão, permanentemente, disponíveis. A frequência dos contatos é intensa e o tempo despendido nas interações é bastante elevado, pela presença quotidiana e pelos inúmeros momentos partilhados conjuntamente.

\section{Considerações finais}

Este artigo pretende contribuir para a visibilidade das fratrias na literatura sociológica e para destacar a sua relevância para a compreensão das dinâmicas familiares. A pesquisa que origina este texto encarou as fratrias na sua complexidade e multiplicidade, defendendo que estas devem ser compreendidas através da diversidade e temporalidade das trajetórias individuais e familiares.

A pesquisa revela traços já conhecidos da sociedade portuguesa acerca da relevância do familismo na construção das relações sociais (Portugal, 2014). Nesse sentido, o texto mostra que os significados do que é ser irmã ou irmão se encontram definidos nos discursos dos sujeitos, e fortemente ancorados nas representações do que é (e do que deve ser) a família. Mas sublinha, também, que o campo das práticas é amplamente desafiado por um conjunto de variáveis, que complexifica o jogo relacional. A fase da infância e da juventude é marcada pela coabitação, e pela interferência das/ os ascendentes que agem como mediadores dessas relações. Mas, com o emergir da idade adulta, colocam-se novos desafios. É na fase de vida adulta que as relações entre irmãs/os se cristalizam de forma mais definitiva, e na qual são mais autónomas relativamente à gestão das suas relações. É nessa altura que a dimensão afetiva joga um papel decisivo.

$\mathrm{Na}$ análise dos discursos perpassa a importância da descoincidência entre as práticas e as representações. Falar da "nossa família”, dos "nossos", 
reveste-se de um significado particular. Devem-se amar as mães e os pais, independentemente, das suas qualidades e dos seus defeitos ou daquilo que fazem (ou não) por seus filhos ou filhas. O mesmo se passa com as irmãs e os irmãos. Se ao nível das representações, o amor fraternal é omnipresente, no âmbito das práticas, as situações são muito diversas. Não se ama todos por igual, nem com a mesma intensidade. A análise das dimensões mais dinâmicas do "que é ser irmã ou irmão" - estatutária e comparativa mostra que as relações fraternais apresentam características específicas, que articulam, de modo particular, no interior da família nuclear, a dicotomia consanguinidade/afetividade.

A identificação das diferentes relações fraternais - vinculativas, companheiristas e de aliança - revelou as especificidades relacionais das fratrias, relativamente aos seus níveis de intimidade e de proximidade. Mostrou, também, como o olhar focalizado nessas relações de parentesco permite complexificar o olhar sobre alguns fenómenos característicos da família contemporânea, como a sua democratização e sentimentalização. As dinâmicas das fratrias revelam como afetividade, afinidade, companheirismo são elementos desafiados por desigualdades estatutárias, de género, de idade, mostrando como o tradicional e o moderno se cruzam num jogo complexo que merece maior atenção das Ciências Sociais, e da Sociologia, em particular.

Como pistas futuras, propõe-se explorar as características dessas relações em contextos mais diversos das realidades familiares: famílias monoparentais, famílias recompostas, famílias homoafetivas, famílias interraciais, entre outras.

\section{Referências}

Atkinson, Robert. (2016). The life story interview. In J. Gubrium \& J. Holstein (orgs.), Handbook of Interview Research (pp.121-140). Thousand Oaks.

Barbas, Andreia. (2014). Crescer a Meias: uma análise sociológica do impacto dos estilos educativos parentais nas relações entre irmã/os. [Dissertação de Mestrado, Faculdade de Economia da Universidade de Coimbra]. http://hdl.handle.net/10316/27360 
Barroso, Margarida. (2011). Social perceptions of siblings' sexual composition: evidence from Portuguese youth. Journal of Comparative Family Studies, 42(5), 687-702. https://doi.org/10.3138/jcfs.42.5.687

Barroso, Margarida. (2008). Fratrias e Género: Contributos para uma análise sociológica das relações fraternais. VI Congresso Português da Sociologia. http://associacaoportuguesasociologia.pt/vicongresso/ pdfs/550.pdf

Barroso, Margarida. (2006). Fratrias na juventude: contributo para uma análise das relações entre irmãos numa abordagem do ciclo de vida [Tese de Licenciatura, Instituto Universitário de Lisboa].

Bedford, Victoria H. (1989). Sibling research in historical perspective: the discovery of a forgotten relationship. American Behavioral Scientist, 33(1), 6-18. https://doi.org/10.1177/0002764289033001002

Bruner, Jerome. (1987). Life as narrative. Social Research, 54, 11-32.

Buisson, Monique. (2003). La fratrie, creuset de paradoxes. L'Harmattan Logiques Sociales.

Burke, Peter, \& Montgomery, Sue. (2000). Siblings of children with disabilities: a pilot study. Journal of Learning Disabilities, 4(3), 227236. https://doi.org/10.1177/146900470000400305

Dalton, Conley. (2004). The pecking order: which siblings succeed and why. Pantheon Books.

Davies, Katherine. (2015). Siblings, stories and the self: the sociological significance of young people's sibling relationships. Sociology, 49(4), 679-695. https://doi.org/10.1177/0038038514551091

Davies, Katherine. (2019). "Sticky" proximities: Sibling relationships and education. The Sociological Review, 67(1), 210-225. https://doi. org/10.1177/0038026118784832

Duncombe, Jean, \& Marsden, Dennis. (2003). The never-ending story: children's gaze and the unresolved narrative of their parents' divorce. In A. Graham \& G. Jones (orgs), Social relations and the life course (pp. 49-62). Palgrave Macmillan.

Edwards, Rosalind et al. (2006). Sibling identity and relationships: sisters and brothers. Routledge.

Elgar, Marian, \& Heah, Ann. (1999). An overview of siblings. In A. Mullender (org.), We are family: sibling relationships in placement and beyond (pp. 19-27). British Agencies of Adoption and Fostering. 
Guerreiro, Maria das Dores et al. (2007). Famílias em mudança: configurações, valores e processos de recomposição. Celta Editora.

Gulløv, Eva, Palludan, Charlotte, \& Winther, Ida W. (2015). Engaging siblingships. Childhood, 22(4), 506-519. https://doi. org/10.1177/0907568214555147

Hamwey, Meghan, Rolan, Emily P., Jensen, Alexander C., \& Whiteman, Shawn D. (2018). "Absence makes the heart grow fonder": a qualitative examination of sibling relationships during emerging adulthood. Journal of Social and Personal Relationships, 36(8), 1-21. https://doi. org/10.1177/0265407518789514

Heath, Sue. (2018). Siblings, fairness and parental support for housing in the UK. Housing Studies, 33(2), 284-298. https://doi.org/10.1080/0267303 $\underline{7.2017 .1291914}$

Kaufmann, Jean-Claude. (1996). L’entretien compréhensif. Éditions Nathan.

Langevin, Annette. (1996). Létude des fratries. In F. de Singly et al. (orgs.), La famille en questions. État de la recherche. Syros.

Merry, Joseph, Bobbitt-Zeher, Donna \& Downey, Douglas. (2020). Number of siblings in childhood, social outcomes in adulthood. Journal of Family Issues, 41(2), 212-234. https://doi.org/10.1177/0192513X19873356

Montandon, Cléopâtre. (2005). As práticas educativas parentais e a experiência das crianças. Educação e Sociedade, 26(91), 485-507. https://doi.org/10.1590/S0101-73302005000200010

Patton, Michael. (2002). Qualitative research \& evaluation methods (3. ed.). Thousand Oaks.

Poeschl, Gabrielle. (2000). Trabalho doméstico e poder familiar: práticas, normas e ideais. Análise Social, 35(156), 695-719.

Portugal, Sílvia. (2014). Famílias e redes sociais: ligações fortes na produção de bem-estar. Edições Almedina, S.A.

Punch, Samantha. (2008). You can do nasty things to your brothers and sisters without a reason: siblings backstage behaviour. Children $\&$ Society, 22(5), 333-344. https://doi.org/10.1111/j.1099-0860.2007.00119.x

Punch, Samantha. (2005). The generationing of power: a comparison of child-parent and sibling relations in Scotland. Sociological Studies of Children and Youth, 10, 169-188. https://doi.org/10.1016/S15374661\%2804\%2910009-3

Roussel, Louis. (1989). La famille incertaine. Editions Odile Jacob. 
Silva, Pedro, Coelho, Conceição, Fernandes, Conceição, \& Viana, Joana. (2011). Usos do computador Magalhães entre a escola e a família: notas de uma pesquisa sociológica [Apresentação de artigo].VII Conferência Internacional de TIC na Educação. https://repositorio-aberto.up.pt/ handle/10216/65156

Smart, Carol. (2006). Children's narratives of post-divorce family life: from individual experience to an ethical disposition. The Sociological Review, 54(1), 155-170. https://doi.org/10.1111/j.1467-954X.2006.00606.x

Steinbach, Anja, \& Hank, Karsten (2018). Full-, half-, and step-sibling relations in young and middle adulthood. Journal of Family Issues, 39(9), 2639-2658. https://doi.org/10.1177/0192513X18757829

Thomson, Rachel et al. (2002). Critical moments: choice, chance and opportunity in young people's narratives of transition. Sociology, 36(2), 335-354. https://doi.org/10.1177/0038038502036002006

White, Lynn. (2001). Sibling relationships over the life course: a panel analysis. Journal of Marriage and Family, 63(2), 555-568. https://doi. org/10.1111/j.1741-3737.2001.00555.x

White, Lynn, \& Riedmann, Agnes. (2016). Ties among adult siblings. Social Forces, 71(1), 85-102. https://doi.org/10.1093/sf/71.1.85

White, Lynn, \& Riedmann, Agnes. (1992). When the Brady Bunch grows up: step/half- and fullsibling relationships in adulthood. Journal of Marriage and the Family, 54(1), 197-208. https://doi.org/10.2307/353287

Widmer, Eric D. (1999). Les relations fraternelles des adolescents. Presses Universitaires de France.

\section{(cc) $\mathrm{EY}$}

Licenciado sob uma Licença Creative Commons Attribution 4.0 